\title{
Design como potencializador na ressignificação de espaços por meio de horta urbana
}

\section{Design as a potentiator in the re-signification of spaces through urban garden}

FIGUEIREDO, Luiz Fernando Gonçalves de; Doutor; Universidade Federal de Santa Catarina

Iff@cce.ufsc.br

VICTORIA, Isabel Cristina Moreira; Mestranda; Universidade Federal de Santa Catarina

Isabel.mvictoria@gmail.com

SOUZA, Luiz Guilherme de; Graduado; Universidade Federal de Santa Catarina

luizdesignufsc@gmail.com

SILVA, Carina Scandarola da; Doutoranda; Universidade Federal de Santa Catarina

cariscan@gmail.com

DIAS, Franciele Vieira; Graduanda; Universidade Federal de Santa Catarina

franciele.vd@outlook.com

VICTORIA, Larissa Moreira; Graduada; Universidade Federal de Santa Catarina

larissa.mvictoria@gmail.com.br

\section{Resumo}

A acelerada urbanização que vem se dando nas cidades, com a criação de diversos espaços comerciais em locais anteriormente ocupados por parques e praças, faz crescer a necessidade da ressignificação de áreas urbanas então marginalizadas. Como agentes sociais, os designers, por meio de ferramentas e técnicas, conseguem atuar no processo de ressignificação desses ambientes, fazendo com que as pessoas sintam-se pertencentes sobre o local, levando inovação e consequentemente socialização à comunidade. As hortas urbanas são bons exemplos de ressignificação de espaços, pois instigam envolvimento e participação de todos. O artigo traz um projeto prático de como o design pode ser um agente potencializador da ressignificação de espaços por meio da implementação de hortas urbanas. Para isso foi utilizada como metodologia o Guia Projetual NASDesign, que se divide em três fases: Sentir, Agir e Realizar.

Palavras Chave: ressignificação; horta urbana; design.

\begin{abstract}
The accelerated urbanization that is taking place in cities, with the creation of several commercial spaces in places formerly occupied by parks and squares, increases the need for the re-signification of urban areas that are then marginalized. As social agents, designers, through tools and techniques, are able to act in the process of re-signification of these environments, making people feel belonging to the place, bringing innovation and consequently socialization to the community. The urban gardens are good examples of redetermination of spaces, since they instigate involvement and
\end{abstract}


participation of all. The article presents a practical project of how the design can be an agent for the enhancement of spaces re - signification through the implementation of urban gardens. For that, the NASDesign Project Guide was used as methodology, which is divided into three phases: Feel, Act and Perform.

Keywords: reassignment; urban vegetable garden; design. 


\section{Introdução}

As cidades se urbanizam com muita facilidade, se os pontos de encontro para socialização de algumas décadas atrás eram as praças e ruas, hoje não são mais devido a incerteza de segurança pública, ao vandalismo e ao aumento da tecnologia e das construções urbanas. Não por acaso a exposição "La Ville Contemporaine - Mutations", realizada entre 2000 e 2001, considerou as principais contribuições da arquitetura contemporânea o ar condicionado e a escada rolante (MORENO, 2002). Ao longo da história pode-se ver claramente que as estruturas urbanas influenciaram o comportamento das pessoas nas cidades (GEHL, 2015).

Entretanto cidade e sociedade cada vez mais se confundem, afinal o que se passa em uma reflete em outra. Sendo assim, a estruturação da cidade reflete o caminhar da sociedade. 160 mil pessoas são acrescidas à população das cidades por dia (MORENO, 2002), dados como esse refletem a importância da cidade nos diálogos da sociedade. Apesar da grande quantidade de pessoas nas cidades, principalmente nas zonas urbanas, não é inteligente atribuir a culpa das fraturas urbanas aos planejadores urbanos, "é enganoso pensar que os centros urbanos modernos são responsáveis pela destruição da experiência humana. As cidades são apenas a manifestação da civilização que adotamos". Ou seja, o desafio de criar cidades confortáveis é de todos.

Para Manzini (2008) os designers atuam como potencializadores da mudança, sendo assim necessário que voltem seus olhares para os espaços urbanos das cidades, contribuindo por meio das diversas ferramentas e métodos de criação do design, com artefatos e serviços para o bemestar das pessoas.

As cidades possuem inúmeros espaços inutilizados (praças, parques, terrenos baldios, entre outros), seja por falta de segurança, vandalismo ou mesmo pela ausência de manutenção. pela falta de segurança, pelo vandalismo ou pela falta de manutenção. Esses espaços são ideais para prospectar inovação social nas comunidades em que estão inseridos. Com sua expertise designers podem ressignificar esses espaços, tornando-os voltados para qualidade de vida dos habitantes. Se as comunidades se tornam ativas na manutenção destes espaços elas passam a sentir pertencimento sobre a cidade, iniciando assim uma cidade viva, que é acolhedora e com integração social, dando a sensação de que o espaço da cidade é convidativo e popular (GEHL, 2015).

Hortas urbanas são uma maneira de ressignificar espaços, devolvendo convívio e socialização para os mesmos, criando um ambiente colaborativo, que incentiva a participação das pessoas na comunidade, uma forma de alimentação saudável e prioriza o bem-estar das pessoas, tudo gerando pertencimento para com o local ressignificado. As hortas urbanas são abordadas como uma forma de expressão coletiva de produção de alimentos e organização local (BIEL \& CABANNES, 2009). Elas são espaços coletivos, de integração e aprendizagem, com forte potencial sociocultural e de melhora na qualidade de vida de quem mantém as hortas e de quem consome (SARAIVA, 2011). As hortas comunitárias possibilitam uma nova visão do alimento, estabelecem relações sociais, encontro de gerações e culturas, contato com o meio e com as plantas, funcionam para interação da comunidade e incorporam a participação ativa da comunidade (HOWE, 2002), além de darem ressignificado ao uso do espaço urbano. "A ideia é facilitar o acesso a alimentos frescos e saudáveis, aumentar as áreas verdes nas metrópoles e diminuir o impacto do transporte de hortaliças, que hoje se baseia em um complexo mecanismo de produção, transporte e distribuição" (FRÓIS, 2015).

Dessa forma, o intuito desse trabalho é evidenciar a participação do design de forma prática 
nesse tipo de intervenção urbana, implementando um projeto acadêmico com o propósito de ressignificar um local marginalizado com a implementação de uma horta urbana.

\section{Metodologia}

Por meio da metodologia do Guia Projetual NASDesign foi possível uma abordagem sistêmica do problema, onde o design é entendido como um processo holístico. O método consiste em três fases: "Sentir", "Agir" e "Realizar" (AROS, 2016). A fase "Sentir" é o primeiro contato com a comunidade, em que define-se a problematização e ocorrem as primeiras experiências com a comunidade estudada, coletando informações e conteúdo para o projeto. A segunda fase é "Agir", nela busca-se desenvolver soluções tangíveis, com o apoio e participação do público-alvo. A terceira fase é "Realizar", e fundamenta-se em implementar a solução final e dar suporte à comunidade se necessário.

\section{Desenvolvimento sustentável}

A expressão "sustentável" provém do latim sustentare (sustentar; defender; apoiar; conservar, cuidar). Em 1987 esse termo foi estendido para "desenvolvimento sustentável" pela comissão Brundtland. O Relatório de Brundtland utilizou a seguinte definição para a expressão "desenvolvimento sustentável": forma como as atuais gerações satisfazem as suas necessidades sem, no entanto, comprometer a capacidade de as gerações futuras satisfazerem suas próprias necessidades (1987). Em resumo, o relatório completa a definição afirmando que o desenvolvimento sustentável é um processo de transformação

no qual a exploração dos recursos, a direção dos investimentos, a orientação do desenvolvimento tecnológico e a mudança institucional se harmonizam e reforçam o potencial presente e futuro, a fim de atender às necessidades e aspirações humanas (CAMARGO, 2003, p.43).

Segundo Manzini (2008) o conceito de "desenvolvimento sustentável" não fornecia indicação a respeito de como esse novo modelo de desenvolvimento deveria ser. Era um conceito abstrato pois apenas afirmava que o modelo proposto inicialmente não era uma proposta praticável. Ao passo de que dizia que outro modelo deveria ser fundado, coerente com alguns princípios básicos (os princípios físicos e éticos da sustentabilidade): uma definição ainda muito vaga, que abriu espaço para inúmeras interpretações, as quais, todavia, foram suficientes para mudar o curso da história.

E em seguida define a expressão "sustentabilidade ambiental". Refere-se às condições sistêmicas a partir das quais as atividades humanas, podendo ser em escala mundial ou em escala local, não destruam os ciclos naturais além dos limites de resiliência dos ecossistemas e não empobreça o capital natural que será deixado para as próximas gerações. $O$ autor define também o termo "sustentabilidade social": refere-se às condições que, seja em escala mundial ou local, as práticas humanas garantam direito ao mesmo espaço ambiental para todos e que as próximas gerações tenham a mesma quantidade e qualidade de recursos que a geração atual.

A transição rumo à sustentabilidade será um processo de aprendizagem social no qual os seres humanos aprenderão gradualmente, através de erros e contradições - como sempre acontece em qualquer processo de aprendizagem -, a viver melhor consumindo (muito) menos e regenerando a qualidade do ambiente, ou seja, do ecossistema global e dos contextos locais onde vivem (MANZINI, 2008, p.27).

Para uma abordagem em relação à sustentabilidade deve-se considerar que a sociedade vive 
em um ecossistema complexo, não sendo uma abordagem correta reduzir a sustentabilidade apenas ao nível ambiental. Dessa forma, a sustentabilidade conceitua-se em se sustentar em três pilares: ambiental, social e econômico (Figura 1). É necessário ter uma visão holística sobre sustentabilidade, buscando uma integração dessas três estruturas da sociedade.

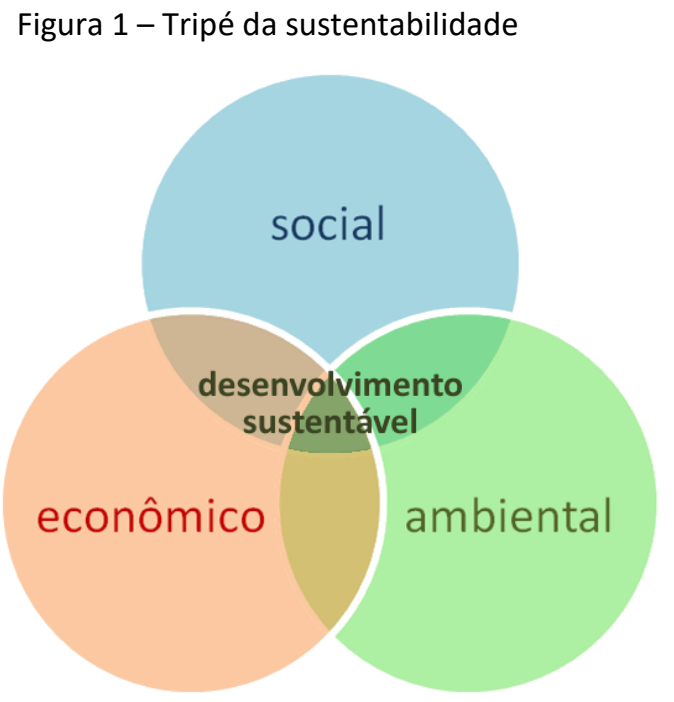

Fonte: http://greenlogic3.blogspot.com.br/2011/04/sustentabilidade-como-poscionamento.html

De forma esquemática, Vezzoli (2010) explica as três dimensões:

- Ambiental: Não ultrapassar a capacidade da terra de absorver os impactos das ações humanas sem provocar fenômenos irreversíveis de degradação.

- Social: Promover uma sociedade socialmente inclusiva, que promove igualdade entre as pessoas. Atender equidade da distribuição de recursos para as gerações futuras.

- Econômica: Viabilizar soluções economicamente viáveis e uma correta atribuição de custos aos recursos.

Thackara (2008) afirma que a sustentabilidade não é uma meta distante de nossa realidade, e que muitos elementos de um ideal sustentável já são reais. Alguns elementos são soluções tecnológicas. Outros provém do mundo natural, graças a todos os anos de evolução natural. Muitas das soluções são compostas de práticas sociais, inclusive práticas muito antigas, mas que evoluíram com o tempo. $O$ autor acrescenta que "A sustentabilidade requer que passemos dos ritmos dos sistemas, que são alto nível de energia, imposto de fora para dentro, e retornemos a um padrão de vida em maior sintonia com os ritmos da biosfera" (THACKARA, 2008, p.70).

\section{Hortas urbanas}

Para Fernanda Knopik (2017), hortas urbanas além de dar um significado ao local de produção e fornecer alimentos mais saudáveis sem o uso de agrotóxicos, está retornado ao conceito de vizinhança realizando uma aproximação da humanidade entre si e com plantio e colheita do meio ambiente.

Considera uma divisão entre privadas e públicas. As individuais localizadas no próprio quintal de casa ou nas coberturas se unindo com o paisagismo do ambiente do apartamento. Com as 
públicas realizando parceira com a comunidade e prefeituras organizando um espaço apropriado nos bairros, praças e parques.

No formato individual o público busca uma aproximação da natureza, relaxar do estresse diário do meio urbano, com uma seleção maior das plantas, produzindo em menor escala por conta do espaço.

No meio urbano a característica principal é a convivência e colaboração, por se tratar de um local de acesso a todos o conhecimento e a integração não deixam de existir bem como a importância do ambiental em local urbano transformando a rotina focada na cidade para a natureza.

\section{Design para Inovação social}

Em sua essência o design busca promover o bem-estar das pessoas, por meio de suas variadas vertentes. No entanto, segundo Manzini (2008), desde o desabrochar da sociedade industrial - que possibilitou o desenvolvimento de ciência e tecnologia mutualmente - vivemos em um bem-estar baseado no consumo de produtos, em que bem-estar significa a obtenção de mais produtos. Entretanto "mais produtos" significa um maior consumo de recursos naturais, logo o aumento de bem-estar está diretamente ligado ao consumo de recursos naturais. Esses recursos naturais não são recolocados na natureza, não gerando nem renovação nem preservação.

A crise econômica exigiu dos países mais maduros industrialmente uma reconsideração sobre esse modelo de bem-estar, buscando formas de viver melhor por meio da diminuição de consumo. Os países em situação econômica oposta, que estão em plena ascensão, as pessoas também estão sofrendo uma mudança socioeconômica e mudando o conceito de bem-estar (MANZINI, 2015).

"Dê um peixe a um homem e o alimentará por um dia. Ensine-o a pescar e o alimentará por toda sua vida" (Lao Tzu, 400 a.C.). Esse antigo ditado mostra duas diferentes alternativas para o mesmo objetivo, no caso a alimentação. Entretanto o ditado mostra como a sociedade se acostumou ao bem-estar baseado no consumo: se está com fome busque um fast food ou algum alimento enlatado. Essa ideia teve início a partir da produção em massa dos bens de consumo, a sociedade passou a ter um complexo sistema de produção de produtos e serviços para atende-la, afim de minimizar o envolvimento pessoal em qualquer serviço. Entretanto, segundo Manzini (2008), os seres humanos podem tender ao prazer em serem servidos, mas podem também comportar-se de modo completamente oposto, sendo possível na natureza humana tanto o caráter passivo como ser ativo e participativo. Os seres humanos são contraditórios, e a partir deste ponto que nasce a proposta de um novo tipo de bem-estar, o bem-estar ativo. Esse tipo de bem-estar traz "a condição na qual somos ativos e cuidamos de nós mesmos, da nossa família, da vizinhança e do ambiente, pois gostamos deles" (MANZINI, 2008 p.55).

A inovação social busca justamente que a sociedade não seja apenas parte do problema, mas seja também parte da solução, ajudando a criar seu próprio bem-estar. A inovação social pode ser conceituada como "mudanças no modo como indivíduos ou comunidades agem para resolver seus problemas ou criar novas oportunidades. " (MANZINI, 2008 p.62). Para o autor, a união desses indivíduos gera as chamadas "comunidades criativas", sendo pessoas que trabalham de forma colaborativa e voluntária para resolução de problemas do dia-a-dia da comunidade, gerando hábitos que podem beneficiar a comunidade de forma econômica e social, além do benefício ambiental que 
essas comunidades podem gerar, contribuindo para a sustentabilidade.

Para Manzini (2015), tratando-se de inovação social não existe um estereótipo dos participantes, então a solução final entre o designer e o usuário torna-se mais nebulosa. Dado este fato, para favorecer a inovação social os designers devem, por meio de ferramentas e métodos projetuais, auxiliar essas comunidades incentivando suas iniciativas. "Uma visão cultural alternativa é vital para moldar as nossas expectativas e impulsionar a mudança transformadora" (THACKARA, 2008 p.51). O autor complementa afirmando que visões compartilhadas são essenciais para dar impulso à inovação. Então o designer deve auxiliar "conversações sociais sobre o que fazer e como fazer" (MANZINI, 2014 p.63), criando um processo de co-design com as pessoas em prol de uma mudança social. Então, para promover a inovação social, designers devem usar suas competências em design para reconhecer casos promissores quando e onde eles surgem e reforçá-los. Isto é, ajudar estes casos a serem mais acessíveis, duradouros e replicáveis.

Sendo assim, é necessário que designers criem condições favoráveis ao diálogo para que as pessoas possam expressar sua criatividade, organizando as informações por meio do seu conhecimento para que as comunidades possam se desenvolver de forma colaborativa e participativa, em que todos se sintam responsáveis pelo seu próprio bem-estar, assim como o da comunidade e do meio ambiente.

\section{Comunidades criativas}

As comunidades criativas, gerando inovação social, tendem a acontecer em duas circunstâncias: quando novas tecnologias surgem na sociedade ou quando problemas urgentes devem ser enfrentados (MANZINI, 2008). Nas últimas décadas muitas novas tecnologias foram criadas e ainda podem ser muito mais exploradas. Quanto aos problemas urgentes, a gravidade dos problemas ambientais e sociais se tornaram óbvios. Em visto disso, temos a combinação dos dois fatores para promoção e crescimento das comunidades criativas.

A criatividade está no âmago da inovação. Fala-se em economias criativas e em comunidades criativas, modelos que se baseiam no fato de que a criatividade é central para o desenvolvimento da sociedade. Dessa forma, cabe ao design criar objetos, mas também situações nas quais a criatividade possa ser exercida não somente pelo designer, mas por todos (CASTRO; CARRARO, 2008, p.796-797).

Comunidades Criativas são inspiradas em iniciativas espontâneas, de pequenos ou grandes grupos de pessoas que desenvolvem trabalhos cooperativos, de uma maneira não convencional, para resolver problemas do dia a dia. Trata-se de uma proposta de um caminho sustentável para o século XXI (MONTENEGRO, 2011). Para Manzini (2008) a sociedade contemporânea e toda sua complexidade pode ser vista como um laboratório de ideias para a vida cotidiana, onde o modo de viver e de resolver problemas são desdobrados e recriados, criando novas oportunidades. Para o autor "Existem muitos casos em que essa criatividade socialmente difusa se expressa no design de atividades que podemos denominar "colaborativas"." (MANZINI, 2008, p.62). Como forma geral, as Comunidades Criativas sempre representam mudanças no seu contexto, pois desafiam a maneira tradicional de fazer, introduzindo novos modos de desempenho, diferente e intrinsecamente mais sustentáveis.

A ideia de que as pessoas resolvam os problemas sociais e ambientais de forma colaborativa, criando novas oportunidades e gerando respostas inéditas pode ser um forte passo rumo a sustentabilidade. Em que a sociedade, de forma conjunta, repara impactos sociais e ambientais, 
criando melhores cenários futuros.

Manzini (2008), destaca três características em comum em qualquer comunidade criativa:

1. Pessoas que, de forma colaborativa, gerenciam e criam soluções inovadoras, usando a criatividade para quebrar modelos dominantes de pensar e agir, criando novos modos de vida.

2. As comunidades criativas nascem a partir de problemas da vida cotidiana contemporânea.

3. Resultam de uma combinação de demandas e oportunidades. Em que demandas são os problemas da vida cotidiana e oportunidades são combinações de três elementos: a existência ou memória de tradições; a possibilidade de usar produtos, serviços e infraestruturas; condições sociais e políticas capazes de aceitar o desenvolvimento de uma criatividade difusa.

Em síntese, pode-se dizer que as Comunidades Criativas são grupos de pessoas dispostas a agir colaborativamente, buscando soluções revolucionárias sem esperar que essas mudanças partam de um novo sistema econômico ou social. Essas pessoas dão um novo significado ao que já existe, aprimorando elementos para que eles se adaptem e resolvam questões da sociedade, criando elas mesmas, novos modos de resolução de problemas da vida cotidiana.

\section{Etapas de projeto}

\section{Primeira etapa: Sentir}

Com a pesquisa aplicada ao público foi realizado um questionário perguntando a compreensão de significado de horta. Para unificar os pensamentos do público foi elaborado uma nuvem de palavras com a somatória das palavras das respondidas, conforme apresentado na figura 2.

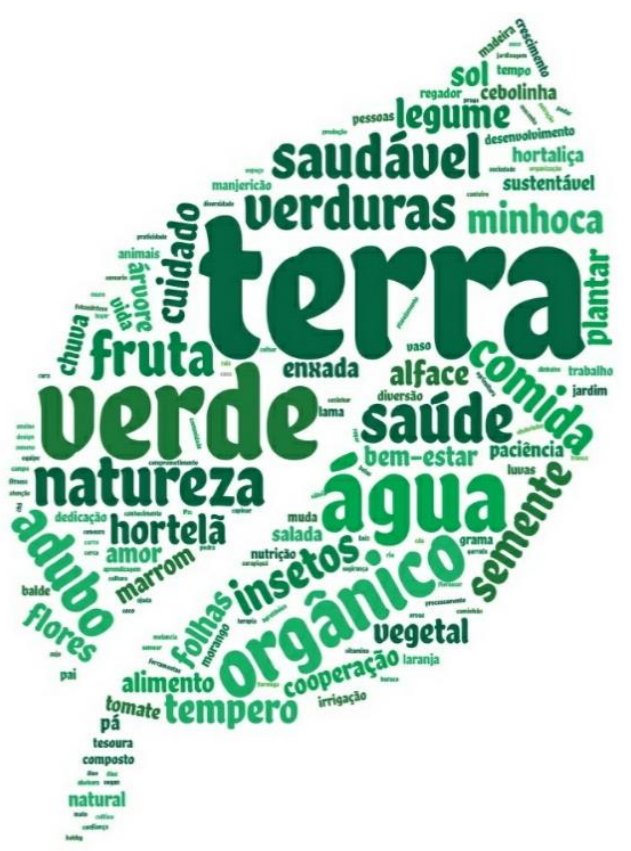


Fonte: Elaborada pelos autores

As principais palavras visualizadas foram: terra e verde. Em segundo plano as palavras: natureza, água, saúde, verduras, orgânico, adubo, minhoca, legumes, fruta e semente.

Foram criados conceitos para o projeto, sendo eles: Sustentabilidade, colaboração e ressignificação. A partir dos conceitos estabelecidos foi elaborado um mapa semântico, afim de entender as relações e compreender seu significado (figura 3 ).

Figura 3 - Mapa semântico

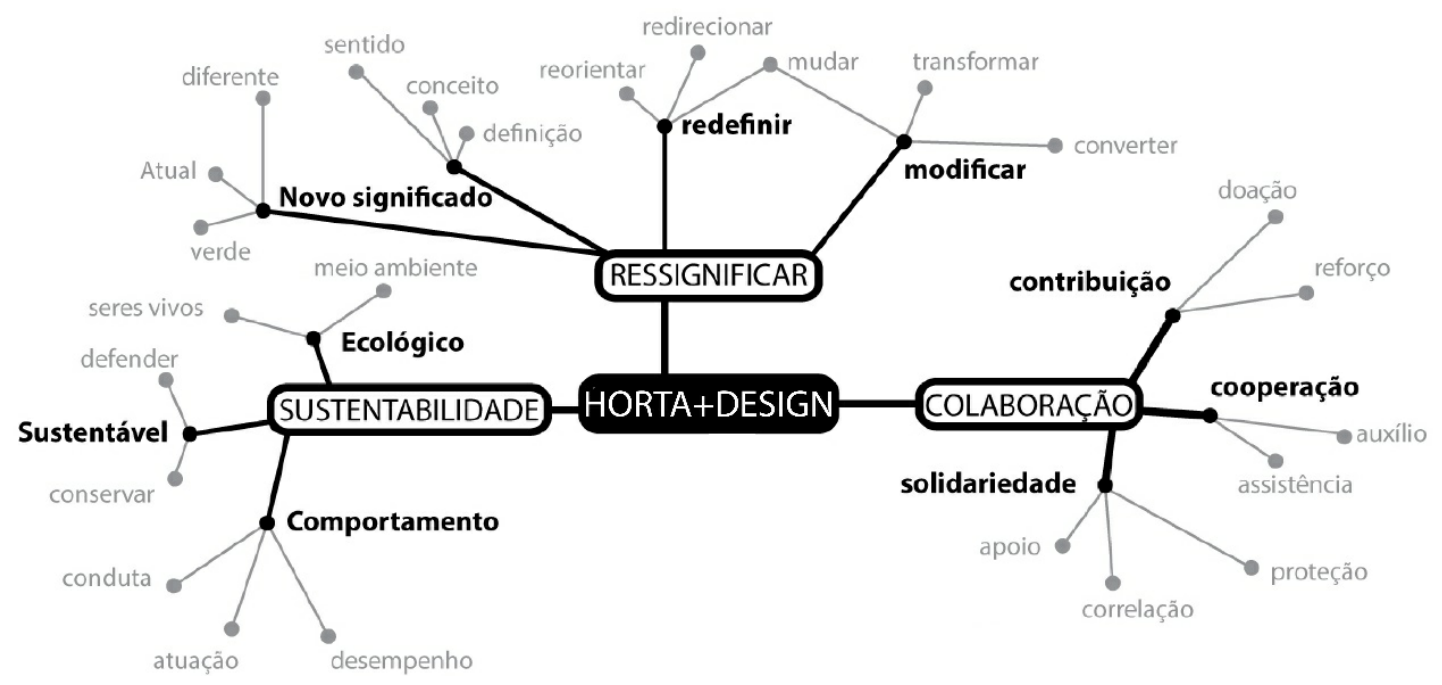

Fonte: Elaborada pelos autores

\section{Identidade visual}

A partir disso foi criada a identidade visual do projeto (figura 4), com a finalidade de padronizar as atividades realizadas.

Figura 4 - Identidade visual

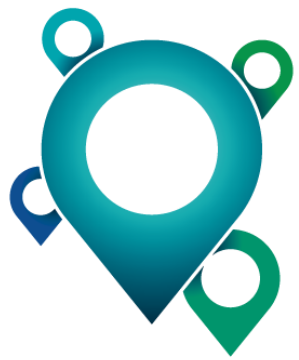

INOVAVERDE

RESSIGNIFICANDO ESPAÇOS

Fonte: Elaborada pelos autores

O formato gráfico desenhado do ícone se assemelha ao alfinete em formato de taça quando 
observado em uma vista superior, possuem duas circunferências com tamanhos distintos. A base do ícone em formato de seta indica o local selecionado como alfinete fixo em um quadro usando de marcação.

A família tipográfica escolhida para construção do logo foi a Montserrat com peso Extrabold. O mesmo peso usado para o complemento textual com escala menor encaixando na proporção lateral da junção "INOVA VERDE".

Optou-se por não inserir um espaço entre as duas palavras para remetendo conceito colaborar, essa proximidade é o que o projeto exige para se manter. No caso da horta serão de extrema importância a manutenção e cuidado do ambiente pelos usuários. Para diferenciar as duas palavras se inserem uma cor em cada termo, ajudando na identificação dos elementos.

Para construção do símbolo se apropriou da letra "O" do nome "INOVA" como base geométrica do ícone de localização. A circunferência utiliza uma proporção de dez blocos de altura para três da seta abaixo. Realizando um corte vertical centralizado podemos observar um equilíbrio entre ambos os lados, assim como o nome "INOVA VERDE" possui a mesma quantidade de letras ocupando espaços quase equivalentes entre cada palavra, com isso o símbolo está em igualdade com a tipografia.

Para futuras aplicações da marca foram elaborados mockups de totens de localização (figura 5), identificando assim em quais locais da cidade existe projetos de horta do Inova Verde.

\section{Figura 5 - Toten}

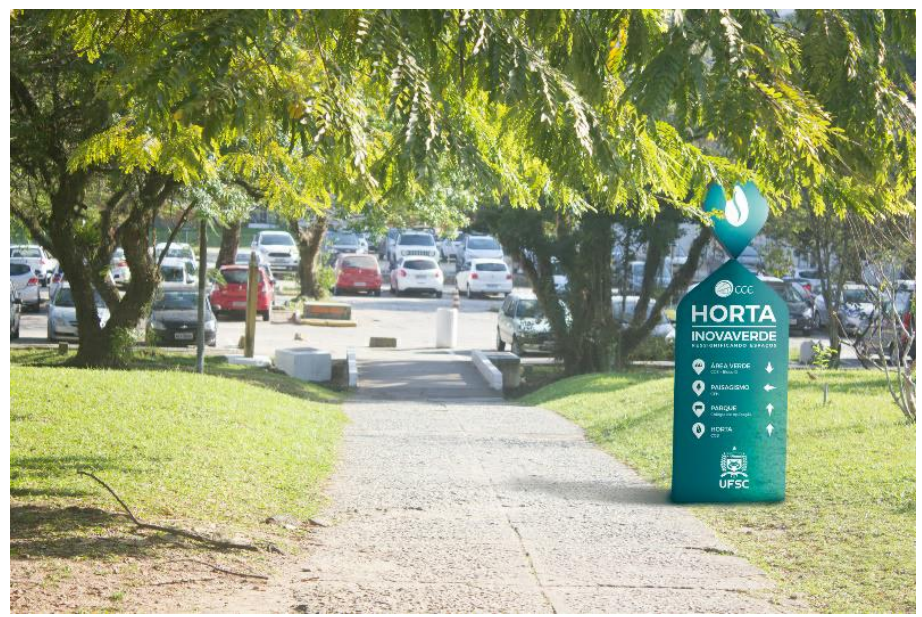

Fonte: Elaborada pelos autores

\section{Segunda fase: Agir}

Na fase de implementação do projeto foi definida uma primeira aplicação no bairro Trindade, dentro de um campus universitário (ambiente público e aberto a qualquer pessoa), que possui comunidade universitária de quase 50 mil pessoas (Censo 2011, Relatório CGPLS) (figura 6). Nessa fase também foi definido o layout do projeto (figura 7). 


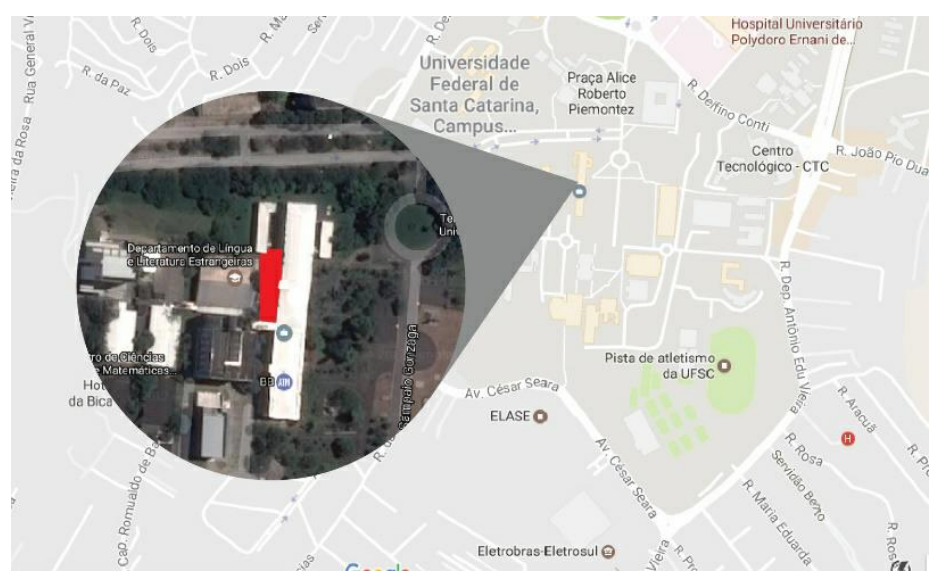

Fonte: Elaborada pelos autores

Figura 7 - Layout do projeto

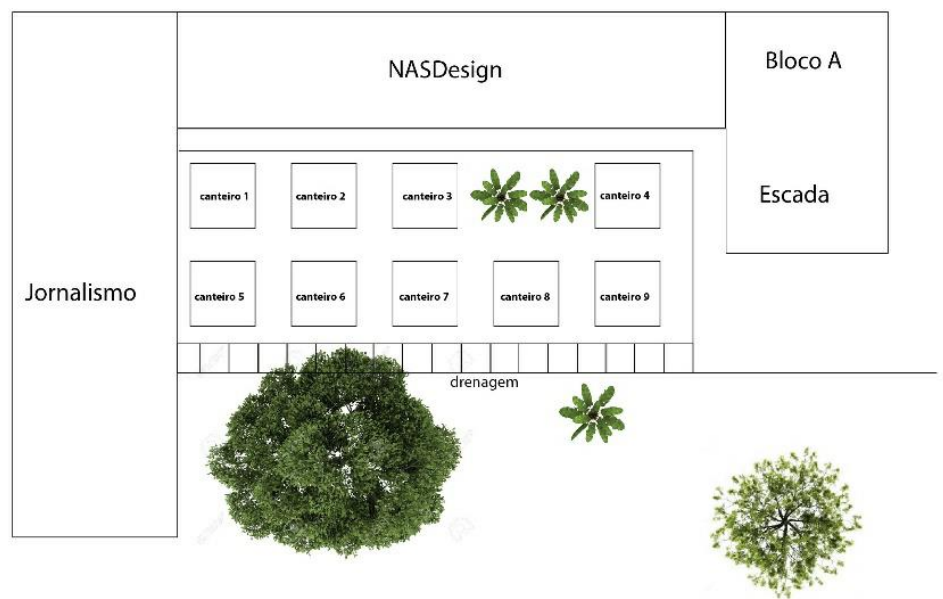

Fonte: Elaborada pelos autores

\section{Terceira fase: Realizar}

A implementação no campus foi autorizada pelos gestores da universidade. Inicialmente os autores do projeto implementaram e iniciaram as manutenções da horta (figura 8). Cerca de três meses depois a comunidade universitária já atua como colaboradores da horta.

Figura 8 - Implementação da horta 


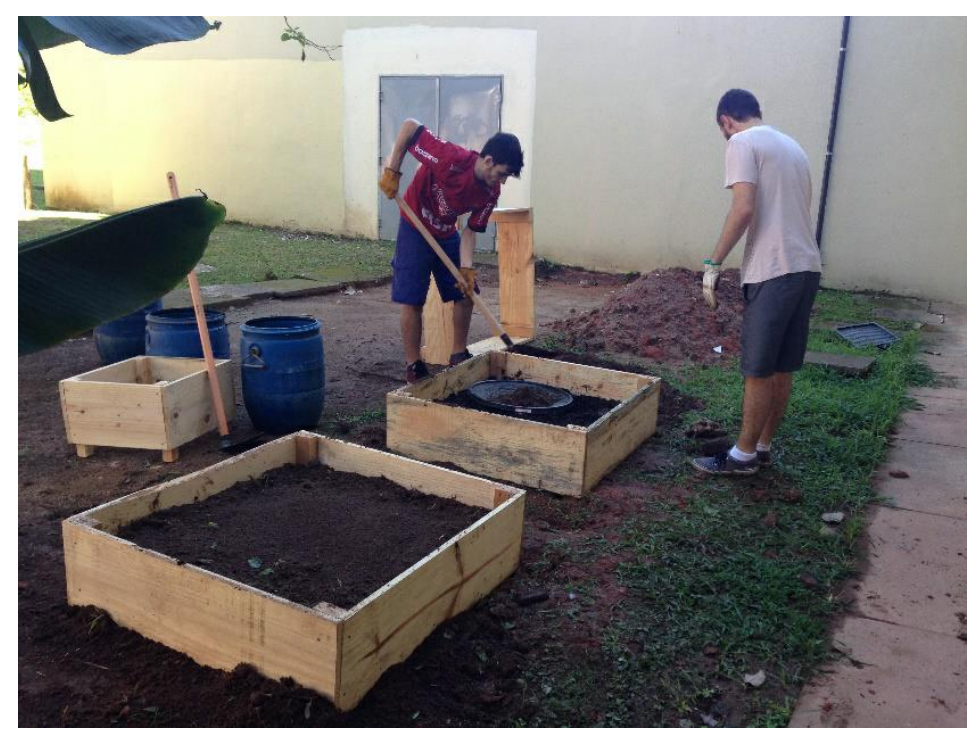

Fonte: Elaborada pelos autores

\section{Considerações finais}

As hortas urbanas são, sem dúvida, um campo muito rico de pesquisas e projetos. O design pode colaborar de diversas formas na implementação de hortas para a ressignificação de espaços. O projeto realizado exemplifica essa oportunidade e, mostra também, algumas das possíveis contribuições do design nesse contexto.

Assim como afirma Thackara (2008), não é recomendável tratar a sustentabilidade como uma meta distante da realidade atual, por isso ações como esse projeto são importantes. A horta urbana criada traz os três pilares da sustentabilidade para o projeto, assim como esquematizadas por Vezzoli (2010). Pensando no contexto ambiental o projeto não degrada o meio ambiente, não impacta negativamente na natureza e ressignifica um espaço marginalizado; no contexto social o projeto traz a comunidade para ações voluntárias em prol de toda a comunidade acadêmica e bairros vizinhos, proporcionando também integração e inclusão; no contexto econômico o projeto possibilita alimentos orgânicos a um custo zero para a comunidade, em que os esforços para cuidados na horta são suficientes para garantir esses alimentos.

Manzini (2008) enfatiza que a comunidade deve ser tratada como foco de inovação social, essa é uma característica importante nesse projeto se faz necessária em outros projetos de design. Pensando nisso, foi escolhida uma metodologia que prioriza o usuário como centro do projeto para que se crie uma solução que realmente faça diferença na vida do usuário, causando bem-estar e o dando autonomia para continuar o projeto. Sendo assim, ter a comunidade como foco de inovação é essencial, motivando o bem-estar social e ambiental. Quando a comunidade sente pertencimento sobre o local ela se sente mais empoderada para tomar novas iniciativas que impactem positivamente o meio social, ambiental e econômico.

No caso desse projeto o espaço ressignificado foi um local dentro de uma universidade pública que estava abandonado, sem cuidados nem da comunidade nem dos gestores da universidade. Essa foi uma grande oportunidade para mostrar formas de designers agirem para ressignificação de espaços. Outros espaços dentro das cidades podem ser ressignificados, como parques, praças, terrenos e outros espaços públicos em desuso, em que podem ser aplicadas outras 
técnicas e ferramentas de design para oportunizar ressignificado: possibilitando, por meio de artefatos, a cooperação entre indivíduos, bem como trazer prazer a eles ao utilizarem estes locais, resgatando as raízes da verdadeira função destes espaços. Além disso também é possível para o design fazer com que as pessoas das comunidades se unam para resolver problemas de forma colaborativa e gerar soluções praticáveis e inovadoras, pensando no melhor para a comunidade no geral e gerando inovação social.

O projeto proporcionou e continuará proporcionando para a comunidade um local de convívio, socialização, com alimentos orgânicos acessíveis e uma transformação no ambiente, que antes estava em desuso e, agora, é frequentado e recebe cuidados pela própria comunidade. Por meio do projeto a comunidade também recebeu conhecimento referente à plantas e alimentação, sendo esse conhecimento repassado pelos autores e por colaboradores da própria comunidade, que já possuíam prévio conhecimento no assunto. Tornou-se um ciclo de ensinamentos, em que todos colaboram, cada um como pode e com o que consegue, e todos aprendem.

Após seis meses de implementação ainda não houve uma replicação do projeto, entretanto espera-se que, com o fechamento do primeiro ano de projeto, sejam integradas novas hortas do projeto em outros bairros da cidade de Florianópolis. Existe a intenção de fazer um mapeamento dessas áreas, controlando o crescimento do projeto e possibilitando auxílios e oficinas para comunidades interessadas na aplicação do projeto, porém sem conhecimento base inicial.

É importante frisar que todos os autores do projeto, assim como atuais e futuros colaboradores devem ser voluntários, não existindo nenhuma troca ou intenção financeira na aplicação do projeto. A ação do projeto tem como consequência proporcionar à comunidade ressignificação de espaços em desuso ou marginalizados, colocando à disposição de todos os benefícios de alimentos, temperos e ervas medicinais orgânicas gratuitamente.

\section{Agradecimentos}

Agradecemos aos gestores do campus universitário pela colaboração e permissão para implementar o projeto. Também agradecemos aos bolsistas Matheus Sauer e João Vitor Meyer pelo trabalho na implantação do projeto.

\section{Referências}

AROS, Kammiri Corinaldesi. Elicitação do processo projetual do Núcleo de Abordagem Sistêmica do Design da Universidade Federal de Santa Catarina. Orientador: Luiz Fernando Gonçalves de Figueiredo - Florianópolis, SC, 2016.

BIEL BIEL, R.; CABANNES, Y. Urban agriculture - the current situation and some pointers to the way forward. London. DPU News. 51. 2009.

BRUNDTLAND, Gro Harlem. Nosso futuro comum: Comissão Mundial sobre Meio Ambiente e Desenvolvimento. 2a. ed. Rio de Janeiro: FGV, 1991.

GEHL, J. Cidades para pessoas. São Paulo: Perspectiva; 2015.

HOWE, J. Planning for urban food: The experience of two UK cities. Planning Practice and Research. 2002

KNOPIK, Fernanda. Arquidicas: Horta Urbana. Disponível em: <http://www.arquidicas.com.br/horta-urbana/>. Acesso em: 11 mai. 2017. 
MANZINI, Ezio. Design para a inovação social e sustentabilidade: Comunidades criativas, organizações colaborativas e novas redes projetuais. Rio de Janeiro: E-papers, 2008. 104 p. (Caderno do Grupo de Altos Estudos do PEP/UFRJ; v.1).

MANZINI, Ezio. Making Things Happen: Social Innovation and Design. Design Issues: v.30 n.1, 2014.

MANZINI, Ezio. Design, when everbody designs: an introduction to design for social innovattion. Cambridge: MIT Press Book, 2015. 241p.

MORENO, J. O futuro das cidades. São Paulo: Ed. SENAC, São Paulo, 2002. 146p.

SARAIVA, R. A. As hortas urbanas na reconfiguração física, social e ambiental do concelho de Oeiras. (Mestrado). Portugal. 2011

THACKARA, John. Plano B: o design e as alternativas viáveis em um mundo complexo - tradução Cristina Yamagami - São Paulo : Saraiva : Versar, 2008. 299 p. 